\title{
La responsabilidad fiscal de los contratistas del Estado
}

\author{
Santiago Fajardo-Peña ${ }^{1}$
}

\section{RESUMEN}

El contrato estatal es una de las más importantes herramientas para la gestión fiscal. La celebración, ejecución y liquidación de contratos estatales también es una fuente potencial de daños patrimoniales al Estado. Quizá por eso, muchos contratistas del Estado son llamados a responder fiscalmente como si fueran auténticos ordenadores del gasto público. La cuestión, sin embargo, no es así de sencilla. El proceso de responsabilidad fiscal tiene un destinatario cualificado: el gestor fiscal. En este artículo, mediante una exposición conceptual y un estudio de caso, se identifican los criterios para determinar en qué eventos un contratista del Estado queda investido de la función de administrar fondos públicos y cuándo puede verse sometido a un proceso de responsabilidad fiscal.

Palabras clave: Contratación estatal, Responsabilidad fiscal, Gasto público, Ejecución presupuestal, Gestión fiscal.

1 Abogado summa cum laude de la Universidad de los Andes, Bogotá, Colombia. Especialista en Derecho Administrativo y Tributario de la Universidad del Rosario, Bogotá, Colombia. Asociado de la oficina Weiner Ariza Moreno Abogados, Bogotá, Colombia. Su práctica profesional se concentra en el litigio y arbitraje en derecho administrativo y derecho público económico. Correo-e: s.fajardo1734@uniandes.edu.co Fecha de recepción: 22 de noviembre de 2016. Fecha de modificación: 8 de marzo de 2017. Fecha de aceptación: 30 de mayo de 2017. Para citar el artículo: Fajardo-Peña, S., "La responsabiliad fiscal de los contratistas del Estado", Revista digital de Derecho Administrativo, n. ${ }^{\circ} 18$, segundo semestre, Universidad Externado de Colombia, 2017, pp. 327-351. DOI: https://doi.org/10.18601/21452946.n18.13 


\section{Fiscal Liability of State Contractors}

\section{ABSTRACT}

The State contract is one of the most important tools for public management. The formation, execution and liquidation of State contracts are also a potential cause of State patrimonial damages. Perhaps for this reason, many State contractors are prosecuted as if they were public spending managers. The question, however, is not as simple. The fiscal liability process has a qualified recipient: the fiscal manager. In this article, through a conceptual exposition and a case study, we identify the criterion for determining in which cases a State contractor acquires the function of controlling public funds and when he/she can be subjected to a fiscal liability.

Keywords: Government Contracting, Fiscal Liability, Public Spending, Budgetary Execution, Fiscal Management.

\section{INTRODUCCIÓN}

"Contraloría embarga bienes a la gerente de Transmilenio: El ente de control determinó que existe un presunto detrimento patrimonial por incumplimiento de un contrato ${ }^{\prime 2}$. Así tituló la revista Semana una noticia del 22 de noviembre de 2016. Y, como aditamento, puso en evidencia un asunto controversial en materia de contratación pública: la responsabilidad fiscal de los contratistas del Estado.

Nadie pone en duda que a un contratista del Estado - la mayoría de las veces- se le paga con fondos públicos por la ejecución de las prestaciones que emanan del contrato estatal. De hecho, tratadistas como Santofimio Gamboa ${ }^{3}$ sostienen que con la entrada en vigencia de la Ley 1150 de 2007, el criterio para determinar la existencia de un contrato estatal dejó de ser exclusivamente orgánico, por lo que esta calificación depende, más bien, de si en el negocio jurídico está involucrada la ejecución de recursos públicos.

El contrato estatal es, cómo no, un negocio jurídico que involucra recursos públicos. Pero, ccuándo puede decirse que un contratista del Estado ejerce gestión fiscal?, o lo que es igual, cen qué casos puede considerarse que este maneja o administra recursos o fondos públicos en virtud de la celebración

2 "Contraloría embarga bienes a la gerente de Transmilenio", Semana, Bogotá, 2016. Disponible en: http://www.semana.com/nacion/articulo/contraloria-embarga-bienes-a-la-gerente-detransmilenio-alexandra-rojas/506273 [consultado el 13 de diciembre de 2016].

3 José Luis Benavides y Jaime Orlando SANTOFimio (comps.), Contratación estatal. Estudios sobre la reforma del Estatuto Contractual, Ley 1150 de 2007. Bogotá: Universidad Externado de Colombia, 2009. 
de un contrato con una entidad estatal? Responder a estas preguntas es el objetivo de escrito.

El volumen de literatura jurídica y decisiones judiciales que hay en el país sobre el tema de la responsabilidad fiscal es relativamente escaso frente a la marcada importancia que tiene esta disciplina en el cumplimiento de un doble objetivo: "reparar a los entes del sector público el menoscabo sufrido en sus bienes o recursos, y satisfacer el interés público vulnerado por quienes, abusando de la confianza depositada en ellos, ocasionan, con la existencia de dolo, culpa o negligencia grave, un perjuicio económico para el Tesoro Público" ${ }^{\prime \prime}$. Este artículo de reflexión pretende contribuir modestamente en la tarea de suplir este vacío.

\section{PLAN DE TRABAJO}

El documento está dividido así: en la primera parte del escrito -sin pretensiones de exhaustividad- se hace una presentación general del concepto de gestión fiscal. En segundo lugar, se estudia la relación que existe entre la gestión fiscal y la ejecución del presupuesto público mediante la celebración de contratos estatales. En este segundo capítulo quedan esbozados los criterios que, en nuestra opinión, son definitorios para establecer en qué casos el contrato estatal conlleva la atribución del ejercicio de la gestión fiscal a particulares.

En la tercera parte del escrito se hace un análisis de caso: se estudia un informe de la Controlaría Delegada para el Sector Infraestructura Física, Telecomunicaciones, Comercio Exterior y Desarrollo Regional sobre presuntos hallazgos fiscales que se presentaron en la ejecución de varios contratos de concesión vial. En el capítulo final, a manera de conclusión, se hace un esfuerzo por registrar los criterios de análisis que se deben tomar en cuenta por las autoridades titulares de la acción fiscal, ordenadores del gasto y demás personas que intervienen en la ejecución de los recursos públicos para determinar en qué casos un contratista del Estado puede ser sujeto de este tipo de responsabilidad.

\section{EL CONCEPTO DE GESTIÓN FISCAL: LÍMITES Y PROBLEMAS DE LA NOCIÓN}

Difícil y antitécnica: estos adjetivos califican, en opinión de los expertos en la materia ${ }^{5}$, la definición de gestión fiscal que se incorporó en el artículo 3 de la Ley 610 de 2000, que dice:

4 Eliseo Fernández Centeno, "Prologo", en Teoría de la responsabilidad fiscal: aspectos sustanciales y procesales, Bogotá: Universidad Externado de Colombia, 2002, p. 24.

5 Uriel Alberto Amaya Olaya, Teoría de la responsabilidad fiscal: aspectos sustanciales y procesales, Bogotá: Universidad Externado de Colombia, 2002, p. 177. 
Para los efectos de la presente ley, se entiende por gestión fiscal el conjunto de actividades económicas, jurídicas y tecnológicas, que realizan los servidores públicos y las personas de derecho privado que manejen o administren recursos o fondos públicos, tendientes a la adecuada y correcta adquisición, planeación, conservación, administración, custodia, explotación, enajenación, consumo, adjudicación, gasto, inversión y disposición de los bienes públicos, así como a la recaudación, manejo e inversión de sus rentas en orden a cumplir los fines esenciales del Estado, con sujeción a los principios de legalidad, eficiencia, economía, eficacia, equidad, imparcialidad, moralidad, transparencia, publicidad y valoración de los costos ambientales.

La gestión fiscal es a la responsabilidad fiscal lo que la cualificación del sujeto activo es a la tipicidad en derecho penal: nadie puede reputarse responsable fiscalmente si no ejerce gestión fiscal. La responsabilidad fiscal-dice el artículo 5 de la Ley 610- está integrada por una conducta dolosa o gravemente culposa ${ }^{6}$ atribuible a una persona que realiza gestión fiscal, un daño patrimonial al Estado y un nexo causal entre los dos elementos anteriores.

Con todo y que este es un elemento estructurador de este especial tipo de responsabilidad, aún persisten muchas dudas sobre el alcance del concepto. Y estas se acentúan todavía más en el caso de los contratistas del Estado. En esta clase de situaciones -en las que se presentan dificultades de elucidación semántica-, Savater ${ }^{7}$ sugiere "retrasar" lo más posible la salida a escena del concepto y merodear antes en torno a este. Algo por el estilo se intenta en seguida. En vez de ensayar una definición concluyente y comprensiva de lo que es la gestión fiscal, se indaga por la función que esta cumple y por las instituciones jurídicas que le dan su propia entidad.

\subsection{LA FUNCIÓN LIMITADORA DEL CONCEPTO DE GESTIÓN FISCAL}

Podría afirmarse, para empezar, que el concepto de gestión fiscal cumple una función limitadora de la competencia constitucional y legal de las contralorías y de la Auditoría General de la República en la determinación de la responsabilidad fiscal. En este sentido, el numeral 5 del artículo 268 superior le atribuye al Contralor General la facultad "establecer la responsabilidad que se derive de la gestión fiscal, imponer las sanciones pecuniarias que sean del caso, recaudar su monto y ejercer la jurisdicción coactiva sobre los alcances deducidos de la misma" (énfasis agregado).

6 Es importante tener en cuenta que en la sentencia C-619 de 2002, M.P.: Marco Gerardo Monroy, la Corte Constitucional equiparó la valoración de la conducta antijurídica para efectos del ejercicio de la acción de repetición o de la derivación de responsabilidad fiscal respecto de los agentes estatales y los gestores fiscales, respectivamente, con en el dolo y la culpa grave, dando aplicación en los dos casos a la preceptiva del artículo 90 superior. Fernando SaVater, El valor de elegir, Madrid: Ariel, 2003, p. 21. 
Ahora bien, si se hace abstracción de los diferentes verbos contenidos en el artículo 6 de la Ley 610 de 2000 se podrá advertir que el concepto de gestión fiscal se reconduce a la facultad de manejar o administrar recursos o fondos públicos. El artículo 2 de la Ley 42 de 1993 parece confirmar esta idea al decir que son sujetos de control fiscal, entre otros, los particulares que manejen fondos o bienes del Estado.

La Sección Primera del Consejo de Estado se manifestó en este sentido en la sentencia del 26 de agosto de $2004^{[8]}$, en la que dijo que los sujetos pasivos en el proceso de responsabilidad fiscal son los servidores públicos y las personas de derecho privado que manejen o administren recursos o fondos públicos, cuando al realizar la gestión fiscal, a través de actividades económicas, jurídicas y tecnológicas, causan un detrimento patrimonial al Estado. Lo propio ha sostenido la Corte Constitucional. En la sentencia C-529 de 1993 esta corporación precisó que de conformidad con la noción generalmente aceptada de que el fisco se integra por bienes o fondos públicos, cualquiera sea su origen, el concepto de gestión fiscal alude a la administración o manejo de tales bienes en sus diferentes etapas de recaudo, conservación, adquisición, enajenación, gasto, inversión y disposición?

Los ingredientes normativos que la dan forma al concepto de gestión fiscal son entonces dos, a saber: i) un objeto: el recurso o fondo público y ii) un poder jurídico: el de administrar tales fondos. Luego, para acotar el concepto de gestión fiscal es necesario establecer, primero, qué se entiende por recurso o fondo público y, además, cuál es naturaleza jurídica y la fuente del poder de manejar recursos públicos.

\subsection{EL CONCEPTO DE FONDO PÚBLICO EN EL DERECHO}

DE LA RESPONSABILIDAD FISCAL

La noción de caudal, fondo o recurso público ha sido estudiada principalmente por hacendistas públicos. Giuliani Fonrouge ${ }^{10}$ señala, por ejemplo, que la noción de caudal público hace referencia al conjunto de dineros y valores existentes en el erario público y, además, a las obligaciones activas a favor del Estado y las corporaciones públicas, como impuestos y derechos pendientes de pago. El fondo público, en sus rasgos más generales, dice este autor, se identifica

8 Consejo de Estado, Sala de lo Contencioso Administrativo, Sección Primera. Sentencia del 26 de agosto de 2004, C.P.: Gabriel Eduardo Mendoza, rad. 2093.

9 Corte Constitucional. Sentencia C-529 de 1993, M.P.: Eduardo Cifuentes Muñoz.

10 Carlos Giuliani Fonrouge, Derecho financiero, Buenos Aires: Ariel, 1996, p. 194. 
con las entradas que obtiene el Estado, preferentemente en dinero, para la atención de las erogaciones determinadas por exigencias administrativas o de índole económica y social.

Sobre el punto, la Corte Constitucional ha sentado las siguientes precisiones:

De la Constitución resulta también, que la noción de renta nacional es un concepto fiscal de carácter general que engloba todos los ingresos del Estado que se incorporan al presupuesto para atender el gasto público. Tales rentas nacionales se integran con los recursos de origen tributario y no tributario y con los recursos de capital. Ese concepto lo trae la propia la Carta cuando señala que al Congreso le corresponde la función de "establecer las rentas nacionales y fijar los gastos de la administración" (art. 150-11) o dispone que "en tiempo de paz no se podrá percibir contribución o impuesto que no figure en el presupuesto de rentas" (art. 345). De igual modo, de la propia Carta se deduce que la clasificación de la renta se elabora atendiendo especialmente la regularidad del ingreso. Por esa razón, se denomina ingresos corrientes a las rentas o recursos de que dispone o puede disponer regularmente el Estado para atender los gastos que demandan la ejecución de sus cometidos, $y$, a su vez, tales rentas se subclasifican como ingresos tributarios y no tributarios. Son, por el contrario, ingresos de capital, aquellas rentas que el Estado obtiene eventualmente cuando es necesario compensar faltantes para asumir gastos en la ejecución de programas y proyectos que se consideran inaplazables. La clasificación precedente de las rentas o ingresos públicos está consignada en la nueva Constitución, y a ella se le atribuyen los mismos alcances que la teoría hacendística le reconoce contemporáneamente a tales nociones. En efecto, los artículos 356 y 357 de la Carta autorizan la participación directa o a través del situado fiscal de los municipios, distritos y departamentos en "los ingresos corrientes de la Nación"; y estos ingresos, según el 358, "están constituidos por los ingresos tributarios y no tributarios con excepción de los recursos de capital". Ahora, como se hizo notar arriba, el concepto de "renta" involucra todos los ingresos públicos, y la noción de "contribución" incorpora tanto los impuestos como los recursos parafiscales (C.P. arts. 150-12 y 338). Se tiene entonces que los impuestos o contribuciones fiscales, por definición, son ingresos públicos, de manera que al identificar la Carta la fuente de aquellos ingresos con los parafiscales, permite afirmar que estos también son ingresos o caudales públicos ${ }^{11}$.

En nuestro medio, el significado de esta expresión en el derecho de la responsabilidad fiscal fue estudiado por la Sala de Consulta y Servicio Civil del Consejo de Estado en un concepto en el que se absolvió una consulta sobre la competencia de la Contraloría para vigilar el manejo de las tasas que retribuyen los servicios prestados por los curadores urbanos. En este concepto se dijo:

11 Corte Constitucional. Sentencia C-308 de 1994, M.P.: Antonio Barrera Carbonell 
La línea jurisprudencial trazada por la Corte Constitucional, es clara al señalar que el control fiscal es una función pública que se ejerce por los organismos de control donde quiera que haya bienes o ingresos públicos. Así las cosas, la pregunta que surge, es ¿Qué se entiende por fondos públicos? ¿son estos únicamente los que se incorporan al Presupuesto General de la Nación o son todos aquellos ingresos cuya fuente es el ejercicio de una función pública, con independencia de la naturaleza jurídica de la persona o entidad que los recauda?

En concepto de la Sala, la noción de fondo público no sólo se circunscribe a los recursos que se incorporan al Presupuesto General de la Nación, sino que abarca todos aquellos fondos que son producto del poder impositivo del Estado, en los términos del artículo 338 de la Constitución Política. En este sentido, la Corte Constitucional en sentencia C-543 de 2001, estableció la diferencia entre recursos de presupuesto y recursos públicos, para concluir que el hecho de que un ingreso no se incorpore al presupuesto, no le resta su calidad de ingreso público. Allí se dijo: "Precisamente en armonía con los mandatos constitucionales (C.P., arts. 267 y 268-4) la gestión que con esos recursos se cumpla está sujeta, entre otros controles, al control fiscal asignado constitucionalmente a la Contraloría General de la República, como sucede en el caso en estudio pues como lo ha expresado la Corte si bien no se trata de recursos presupuestales sí son recursos públicos de la Nación".

En consecuencia, hoy por hoy, la noción de fondo público va más allá del concepto restringido de la incorporación al presupuesto, siendo determinante para dar dicha calificación que el recurso se origine en la soberanía impositiva del Estado, aunque no ingrese al presupuesto. Así las cosas, si la tasa es una contribución que emana del poder impositivo del Estado, cuyo hecho generador es la prestación concreta e individualizada de un servicio público de carácter administrativo, no hay duda para la Sala, [de] que estas representan un ingreso o fondo público, independientemente de la naturaleza jurídica, pública o privada, de la persona que lo recaude y maneje y de su incorporación o no al Presupuesto.

[ ... A Ahora bien, en concepto de esta Sala, para determinar cuándo un particular que realiza funciones públicas es sujeto de control fiscal, no basta analizar la naturaleza de la función que desempeña y la de los recursos que recauda o percibe, sino que es indispensable, además, verificar si realiza actos de gestión fiscal, en los términos estatuidos en la ley 610 de 2000.

Lo anterior, con el fin de evitar que a la postre se desdibuje el alcance y los fines del control y se caiga en el extremo de exigirlo para aquellos que reciben recursos públicos en forma precaria, como es el caso de los particulares agentes retenedores de impuestos, quienes no tienen facultad alguna de manejo y administración sobre esos fondos ${ }^{12}$.

12 Consejo de Estado, Sala de Consulta y Servicio Civil. Concepto del 3 de febrero de 2005, C.P.: Gustavo Aponte Santos, rad. 1.624. 
Según la jurisprudencia que hay sobre el tema, el fondo público es cualquier recurso o bien -material o inmaterial- que se posee o se percibe en virtud de la soberanía impositiva del Estado. Esta calificación -la de fondo público- no depende de la integración del recurso al presupuesto de rentas, vale decir, al cumplimiento del principio presupuestal de unidad de caja. Ni tampoco depende de la naturaleza pública o privada de la persona quien lo administra. Por esa razón, las tasas retributivas de servicios públicos -como el peaje pagado el usuario de una vía concesionada- o la contribución lechera y ganadera (exacción de carácter parafiscal) se clasifican como fondos o recursos públicos. Porque aun cuando su administración le compete a órganos gremiales como la Federación Nacional de Cafeteros y no a entidades estatales, los recursos se originan en gravámenes establecidos en la ley con carácter obligatorio.

\subsection{El PODER DE DISPOSICIÓN JURÍDICA DE FONDOS PÚBLICOS}

ES UNA FUNCIÓN ADMINISTRATIVA

En la doctrina se ha destacado que la gestión fiscal expresa el ejercicio de una función administrativa ${ }^{13}$. La conclusión, en nuestra opinión, es correcta. Sin embargo, afirmar que la gestión fiscal es una manifestación de la función administrativa trae consigo el problema de elucidación semántica al que nos referíamos al inicio de esta sección. Dice con razón Palacios Mejía ${ }^{14}$ que el concepto de función administrativa es tan difícil de elaborar como el de servicio público. Por eso, para los fines de este artículo nos conformaremos con asumir que la gestión fiscal es una expresión de la función administrativa en tanto que no es función legislativa (pues no supone la creación de normas de carácter general, abstracto e impersonal) ni es función judicial (en la medida que administrar fondos públicos está muy lejos de la función estatal de adjudicar derechos y dirimir disputas).

Por sencilla que parezca esta aproximación, este criterio sigue teniendo aceptación entre los exponentes del positivismo legal ${ }^{15}$. Se dice que la función administrativa comprende toda actividad estatal que, considerada en sí misma, no es un acto legislativo ni jurisdiccional. Garrido Falla ${ }^{16}$ complementa esta explicación al señalar que la definición negativa del concepto de función administrativa responde a un dato histórico: los

13 Rodrigo NaRANJo Galves, Eficacia del control fiscal en Colombia: derecho comparado, bistoria, macroorganizaciones e instituciones, Bogotá: Universidad del Rosario, 2007, p. 190.

14 Hugo Palacios Mejía, El derecho de los servicios públicos, Bogotá: Derecho Vigente, 1999, p. 32.

15 Ver Jaime Santofimio Gamboa, Tratado de derecho administrativo, Bogotá: Universidad Externado de Colombia y Universidad Carlos III de Madrid, t. I, 1996, pp. 99-115.

16 Fernando Garrido Falla, Tratado de derecho administrativo, Madrid: Tecnos, vol. 1, 1989, pp. 36-41. 
poderes legislativos y judiciales se formaron con las competencias que progresivamente le fueron arrancado al antiguo monarca absoluto. Y lo que quedó de función administrativa es justamente lo que resulta del poder del monarca una vez se hacen las anteriores sustracciones.

Este acercamiento a la noción de gestión fiscal y a su aplicación en materia de contratación estatal tiene, con todo y sus limitaciones conceptuales, una importante ventaja explicativa. Si asumimos que la gestión fiscal es una expresión de la función administrativa, podemos concluir que para adquirir la calidad de gestor fiscal se requiere de un título jurídico habilitante. No estamos diciendo nada diferente a que un contratista del Estado solo puede reputarse gestor fiscal a condición de que se le haya atribuido la potestad administrativa de gestionar bienes o fondos públicos. Esa es la esencia del principio de legalidad administrativa.

La delegación de funciones administrativas a particulares, incluyendo contratistas del Estado, se aborda, casi siempre, desde el punto de vista de la descentralización por colaboración. Se afirma, en consecuencia, que el ejercicio de funciones administrativas por parte de particulares debe estar precedido por la expedición de una ley o un acto administrativo para que se garantice el principio de legalidad administrativa. Es por eso que el inciso segundo del artículo 210 CP determina que "los particulares pueden cumplir funciones administrativas en las condiciones que señale la ley", y que el artículo 110 de la Ley 489 de 1998 señala que la atribución de funciones administrativas debe estar precedida de acto administrativo y acompañada de convenios, si fuere el caso. Es decir que si un particular maneja fondos públicos debe estar amparado por una ley o acto administrativo. Este caso, relativamente sencillo, es el de las cámaras de comercio y el de los curadores urbanos.

Frente a las cámaras de comercio se ha admitido pacíficamente que ejercen gestión fiscal y, por ende, pueden quedar sometidas al proceso de responsabilidad que disciplina la Ley 610 de 2000. El Código de Comercio, desde el año 1971, así lo previó en su artículo 88 al consagrar que "la Contraloría General de la República ejercerá el control y vigilancia del recaudo, manejo e inversión de los ingresos de las cámaras de comercio, conforme al presupuesto de las mismas, previamente aprobado por la Superintendencia de Industria y Comercio". Y así lo ratificó la Corte Constitucional en la sentencia C-167 de 1995, en la que dijo:

Para esta Corporación es racional entender que si el registro mercantil implica la prestación de un servicio público, su financiamiento debe asegurarse mediante un ingreso percibido por la Cámara de Comercio en forma de tasa, cuyo destino 
no es el acrecimiento del patrimonio de la entidad, tal como lo entiende el libelista sino [...] asegurar la adecuada prestación de este servicio público, vale decir [...] la recuperación del costo total o parcial del servicio, que es consustancial a la naturaleza de este ingreso público. Si bien es cierto que no es objeto de discusión por parte del libelista, conviene precisar y recordar la jurisprudencia de esta Corporación (Sentencia C-465 de 1993), en donde se estableció el concepto de tasa como ingreso tributario, para concluir que, en este caso específico, este ingreso no se puede considerar como ingreso privado de las Cámaras de Comercio.

En conclusión, la tasa creada por la Ley 6a. de 1992, no es un recurso privado de las Cámaras de Comercio, sino que se constituye en un recurso público, toda vez que surge de la soberanía fiscal del Estado, no de la voluntad individual entre los particulares comerciantes, pues únicamente posee el propósito de financiar la función pública del registro mercantil; no es un título adquisitivo de dominio para la persona jurídica de derecho privado que la presta, ya que el ejercicio de las funciones públicas atribuidas a las personas jurídicas se hallan sujetas [sic] a las reglas propias de la función administrativa ejercida, pues, en virtud de la habilitación, ocupan el lugar de la autoridad estatal con sus deberes y prerrogativas; en consecuencia, los recursos económicos provenientes del ejercicio de tales funciones, como el registro público mercantil, se traducen en la generación y conformación de fondos públicos ${ }^{17}$.

Lo dicho hasta acá permite formular otra conclusión: el ejercicio de la gestión fiscal por parte de particulares, en tanto función administrativa, se fundamenta en la atribución que, mediante ley o acto administrativo, hace una autoridad pública a un particular.

Pero no son estos dos los únicos títulos jurídicos que habilitan a un particular para que ejerza la gestión fiscal. Porque el contrato estatal, como negocio jurídico que es, no goza de los atributos de la ley y el acto administrativo y, aun así, la Corte Constitucional ha admitido que el mismo sea, excepcionalmente, uno de los instrumentos para atribuir a particulares la facultad de ejercer gestión fiscal. En la sentencia C-563 de 1998, la Corte dijo:

En las circunstancias descritas, el contratista se constituye en un colaborador o instrumento de la entidad estatal para la realización de actividades o prestaciones que interesan a los fines públicos, pero no en un delegatario o depositario de sus funciones.

Sin embargo, conviene advertir que el contrato excepcionalmente puede constituir una forma, autorizada por la ley, de atribuir funciones públicas a un particular; ello acontece cuando la labor del contratista no se traduce y se agota con la simple ejecución material de una labor o prestación específicas, sino en el desarrollo de 
cometidos estatales que comportan la asunción de prerrogativas propias del poder público, como ocurre en los casos en que adquiere el carácter de concesionario, o administrador delegado, o se le encomienda la prestación de un servicio público a cargo del Estado, o el recaudo de caudales o el manejo de bienes públicos, etc.

En consecuencia, cuando el particular es titular de funciones públicas, correlativamente asume las consiguientes responsabilidades públicas, con todas las consecuencias que ella conlleva, en los aspectos civiles y penales, e incluso disciplinarios, según lo disponga el legislador ${ }^{18}$.

¿Cuáles son esos casos excepcionales en los que el contrato estatal se constituye como un instrumento idóneo para que un particular adquiera la condición de gestor fiscal? ¿Qué características especiales reviste el contrato estatal en el que se atribuye la función administrativa de ejercer gestión fiscal? Responder a estas preguntas es el objetivo del siguiente capítulo.

\section{EL CONTRATO ESTATAL COMO INSTRUMENTO DE GESTIÓN FISCAL}

El contrato estatal es, ante todo, un instrumento de gestión pública para la provisión de bienes y servicios a los asociados. Este acercamiento instrumental a la noción de contrato estatal es un lugar común entre los estudiosos de la materia. Palacio Jaramillo afirmaba, no mucho después de la expedición de la Ley 80 de 1993, que la "contratación pública no constituye un mero cuerpo normativo para regular cuestiones puntuales y formales, sino que es la columna vertebral del movimiento de la riqueza y la manera como el país, su industria, su sector empresarial [...] se vincula al engranaje económico" ${ }^{\prime 19}$. El mismo acercamiento - no legalista- al contrato estatal sigue marcando la pauta en los debates legislativos de mayor actualidad. Por ejemplo, en la exposición de motivos del proyecto de ley elaborado en el año 2016 por la Agencia Nacional de Contratación Pública se hacen las siguientes consideraciones:

El Sistema de Compra Pública (Public Procurement System) es la estructura organizada creada por los Estados para tomar decisiones de gasto público con el propósito de poner a disposición de las personas bienes, obras y servicios. En Colombia, desde la creación de la Agencia Nacional de Contratación Pública -Colombia Compra Eficiente-, ha habido una discusión teórica sobre la denominación del Sistema. Aquellos con un enfoque económico prefieren la expresión compra pública, mientras que los que tienen un enfoque jurídico prefieren la expresión contratación pública.

18 Corte Constitucional. Sentencia C-563 de 1998, M.P.: Carlos Gaviria Díaz.

19 María Teresa Palacio Jaramillo, "Parámetros constitucionales para la determinación de un régimen jurídico de contratación pública en Colombia", Revista de Derecbo Público de la Universidad de los Andes, n. ${ }^{\circ}$ 14, 2002, p. 27. 
Los primeros argumentan que la contratación pública es solamente un elemento del Sistema de Compra Pública y que la compra incluye todas las decisiones de gasto, la planeación y las actividades propias del abastecimiento y de la ejecución de proyectos, incluyendo los contratos y la entrega de bienes, obras o servicios y las obligaciones postconsumo. Los segundos dicen que la expresión contratación pública cubre todo el proceso de adquisición de bienes, obras y servicios, además de otros tipos de negocios jurídicos como las Asociaciones Público Privadas y el pago de las obligaciones que surgen de los $\operatorname{contratos}^{20}$.

Cabe recordar que antes de la expedición de la Ley 80 de 1993 las normas sobre contratación administrativa no conformaban un cuerpo único, sino que el régimen legal del contrato público era, más bien, un apéndice de los estatutos fiscales de las entidades territoriales. En este sentido, De Vivero sostiene que en vigencia del Decreto Ley 222 de 1983 existían tantos regímenes de contratación como entidades territoriales que hubiesen creado regulaciones en materia contractual en sus códigos fiscales ${ }^{21}$.

Podemos decir, en resumen, que el contrato estatal es un instrumento -quizá el más importante- de ejecución del presupuesto público y de gestión fiscal. Ahora bien, es preciso establecer en qué casos el contrato estatal habilita a un particular para que sea él y no la entidad estatal la gestora de los recursos públicos.

Los criterios de análisis para responder a esta pregunta los perfiló la Sección Primera del Consejo de Estado en un reciente pronunciamiento, en el que dijo:

$[\mathrm{N}]$ o se pueden hacer juicios generalizados como lo hizo la apelante, en el sentido de que siempre que un particular suscriba un contrato estatal-que per se debe involucrar la ejecución de recursos públicos de lo contrario no tendría esta condición-, por este sólo hecho, el particular desplegó gestión fiscal y por ende estaría incurso en este tipo de responsabilidad. Lo anterior, por cuanto para que tenga acogida esta afirmación, se debe mirar cada caso en particular para determinar con fundamento en el tipo de contrato cuestionado, si el particular que manejó o administró bienes o recursos públicos, se desempeñó como gestor fiscal ${ }^{22}$.

El análisis de si un contratista del Estado cumple el papel de gestor fiscal es, entonces, casuístico: se debe determinar, conforme el objeto del respectivo

20 Agencia Nacional Colombia Compra Eficiente, Exposición de Motivos del Proyecto de Ley por medio del cual se establecen los principios y reglas aplicables a los Procesos de Abastecimiento de bienes, obras y servicios de las Entidades Estatales, p. 14.

21 Felipe de Vivero ArCiniegas, "La jurisprudencia del Consejo de Estado: añoranza del Decreto 222 de 1983", Revista de Derecho Público de la Universidad de los Andes, n. ${ }^{\circ}$ 12, 2001, p. 235.

22 Consejo de Estado, Sala de lo Contencioso Administrativo, Sección Primera. Sentencia del 12 de noviembre de 2015, C.P.: María Claudia Rojas, rad. 2004-01667-01. 
contrato, si el particular se arrogó la facultad de manejar o administrar recursos públicos.

\subsection{El CONTRATISTA ES GESTOR FISCAL SI DisPONE \\ DE RECURSOS PÚBLICOS, NO PRIVADOS}

La primera consideración que se puede extraer de lo dicho por el Consejo de Estado es que el solo hecho de suscribir un contrato estatal (que per se involucra la ejecución de recursos públicos pues de lo contrario no tendría esta condición) no es sinónimo de que el contratista despliegue gestión fiscal.

El contrato estatal siempre involucra la ejecución de recursos públicos porque con ellos se paga al sujeto contratista privado. Sin embargo, este solo podrá reputarse gestor fiscal si gestiona fondos públicos, no recursos privados. Para vislumbrar un poco mejor la cuestión es necesario establecer en qué eventos el recurso público que se ejecuta mediante el contrato estatal deja de ser público para convertirse en privado y en qué casos el recurso público conserva dicho rasgo distintivo, a pesar de aplicarse a la ejecución de un contrato celebrado con un particular.

Cuando se entra a analizar si un contratista despliega gestión fiscal esta es la primera incógnita que se debe despejar. El Consejo de Estado no ha examinado a fondo esta cuestión. En nuestra opinión, el criterio que se debe usar para determinar si el recurso ejecutado en virtud del contrato estatal es público o privado es si el mismo entra al patrimonio del contratista, vale decir, si se le $d a^{23}$ a título de pago o si, por el contrario, el contratista lo gestiona por cuenta de la entidad estatal. La solución que proponemos se fundamenta, en últimas, en las más básicas instituciones del derecho civil.

El recurso afecto al contrato estatal pierde su calidad de fondo público cuando con él se le paga al contratista por el cumplimiento de las prestaciones que se originan en el contrato estatal. Diríamos, en otras palabras, que la ejecución del contrato estatal siempre involucra recursos que en su origen son públicos, pero que pierden esa condición si se aplican al pago del contratista privado y, por ello, entran a su patrimonio.

Pagada la obligación de la entidad estatal de dar una suma de dinero mediante la tradición, el recurso -en su origen público-entra al activo patrimonial del contratista y, por ende, pierde dicha calidad, convirtiéndose en privado y otorgando al beneficiario del pago libertad de disposición del activo. Luego, 
con independencia del cumplimiento de sus obligaciones, si el contratista privado ha recibido a título de pago fondos públicos no podrá ser perseguido fiscalmente, por la sencilla razón de que no gestiona fondos públicos, sino que dispone de recursos privados. En este mismo sentido se expresa Dávila Vinueza al sostener:

... las sumas de dinero una vez salen del patrimonio estatal para ser recibidas por los contratistas como contraprestación de sus servicios o las que se le entregan a título de restablecimiento del equilibrio económico y financiero del contrato, en manera alguna encuadran dentro del concepto de manejo de recursos oficiales, lo que, en consecuencia, derivaría en la imposibilidad de perseguir fiscalmente por esos conceptos ${ }^{\prime \prime 24}$.

El criterio analizado explica adecuadamente por qué, en tratándose de anticipos, el contratista privado sí puede verse sometido a un proceso de responsabilidad fiscal. Aunque el asunto no está exento de controversia ${ }^{25}$, en materia de contratación estatal se ha dicho que la diferencia entre los conceptos de pago anticipado y anticipo está dada por la destinación que debe darse a dichas sumas.

[M]ientras el anticipo se entrega al contratista para que este invierta en la ejecución del contrato y por ello no ingresa al patrimonio del contratista sino que sigue perteneciendo a la entidad que lo gira, el pago anticipado, es simplemente la remuneración entregada antes de que se cumplan las obligaciones contractuales del contratista, de modo que puede ser gastada por este sin ninguna limitación ${ }^{26}$.

24 Luis GuILleRmo DáviLA, Régimen jurídico de la contratación estatal: aproximación crítica a la Ley 80 de 1993, Bogotá: Legis, 2. ${ }^{a}$ ed., 2003, p. 587.

25 En algunas providencias, que no son mayoría, la Sección Tercera del Consejo de Estado ha rechazado la distinción entre anticipo y pago anticipado, como se lee en este aserto: "Siguiendo el lineamiento trazado, la Sala concluye que el anticipo que por virtud de la celebración de un contrato estatal se entrega al contratista, lejos de corresponder a un préstamo, en realidad constituye una modalidad de pago que las partes en desarrollo del principio de la autonomía de la voluntad libremente pueden convenir, cuya diferencia en relación con el pago anticipado resulta casi imperceptible y a la postre infructuosa. Ciertamente, tampoco resulta acertado considerar que el gran rasgo diferenciador que existiría entre el anticipo y el pago anticipado consista en que el manejo que el contratista imprima al primero de ellos debe estar debidamente justificado en la ejecución del contrato, mientras que el pago anticipado entraría al haber del contratista quien podrá disponer del mismo como a bien lo tuviera, pues en modo alguno puede pasarse por alto que en el evento de presentarse un incumplimiento contractual imputable al contratista, este siempre tendrá que responder, atendiendo a las debidas proporciones, ya sea por la cantidad entregada a título de anticipo o por aquella recibida como pago anticipado": Consejo de Estado, Sala de lo Contencioso Administrativo, Sección Tercera. Sentencia del 12 de febrero de 2014, C.P.: Mauricio Fajardo Gómez, rad. 31682

26 Consejo de Estado, Sala de lo Contencioso Administrativo, Sección Tercera. Sentencia del 7 de septiembre de 2015, C.P.: Olga Mélida Valle, rad. 36878. 
Si el anticipo se entrega como medio de financiación de las actividades contratadas y no como pago de las prestaciones ejecutadas por el contratista, este no entra a su patrimonio, conserva su calidad de fondo público y, por eso, su malversación, uso indebido o pérdida es un hecho generador de la responsabilidad fiscal del contratista.

Es cierto que en la técnica contable y jurídica el anticipo se registra como una cuenta por pagar del contratista. Sin embargo, esta no es, en un sentido estricto, la razón que explica por qué el contratista se reputa como gestor fiscal de dichos fondos. Porque, por ejemplo, en un contrato de cuenta corriente celebrado entre una entidad pública y una entidad financiera privada, esta última tiene disponibilidad de recursos públicos y, no obstante, su pérdida no necesariamente es generadora de responsabilidad fiscal. Lo que queremos significar con esta afirmación es que no basta la disponibilidad material del recurso público para que un contratista del Estado adquiera la calidad de gestor fiscal. Es preciso que el contratista, como se ha venido diciendo, tenga disponibilidad jurídica de los fondos públicos.

\subsection{EN VIRTUD DEL CONTRATO ESTATAL SE DEBE OTORGAR AL CONTRATISTA DISPONIBILIDAD JURÍDICA, NO SOLO MATERIAL, DEL RECURSO PÚBLICO}

Ya hemos dicho, a manera de conclusión preliminar, que el contratista es gestor fiscal si dispone de recursos públicos, no privados. Y que el fondo público afecto a un contrato estatal pierde esa condición en el momento en que entra al patrimonio del contratista privado, esto es, cuando se le transfiere a título de pago. Esto no quiere decir que en todos los casos en los que un contratista del Estado tenga disponibilidad de fondos públicos ostente la condición de gestor fiscal. Es preciso, según lo expresado en el acápite anterior, que la disposición de los recursos sea una disponibilidad cualificada: una disponibilidad jurídica y no solo material. Habrá disponibilidad jurídica cuando el contrato estatal tenga por objeto la delegación de la función administrativa de ejercer gestión fiscal y no, simplemente, cuando con ocasión del respectivo contrato el contratista entre en posesión material de los fondos públicos.

Uriel Amaya explica esta distinción en los siguientes términos:

La gestión fiscal, entonces, le concede al servidor público -o de manera excepcional al particular-, por vía funcional o contractual, no sólo una disponibilidad material sobre el patrimonio público, sino esencialmente una disponibilidad jurídica sobre el mismo. Es decir, la capacidad jurídica para disponer del mencionado patrimonio de manera válida y legítima, como producto del límite reglado señalado en las normas jurídicas -o en el objeto contractual, en tratándose de este-que le otorgan competencia para ello. 
[...] Por tal razón, existe un sinnúmero de actuaciones simplemente administrativas que no comportan actos propios de gestión fiscal: un servidor público de una entidad que se apropia de un bien de la misma, sobre el cual no tiene disponibilidad jurídica (aunque sí material: por laborar, p. ej., en el mismo edificio donde se encuentra el bien [...]); o la compañía de vigilancia privada que mantiene un contrato con una entidad pública y por desidia de los celadores se produce un hurto sobre los bienes públicos; o del ladrón que ingresa a una edificación pública y hura bienes de esa naturaleza. En todos estos casos no habría responsabilidad fiscal, por no existir gestión fiscal propiamente dicha por parte de tales agentes.

A estas situaciones agregamos otros ejemplos en los cuales no existe el vínculo jurídico determinante que limita no sólo la configuración sustancial de la responsabilidad fiscal, sino el ejercicio mismo de la acción procesal, relativo a la condición de rango constitucional denominada gestión fiscal.

Es el caso de un banco que mantiene un contrato de cuenta corriente con una entidad pública, y por negligencia de sus empleados se produce un daño sobre los recursos de dicha entidad allí depositados [...].

[... Una eventual responsabilidad patrimonial del banco por los hechos señalados en el ejemplo es de carácter contractual privado, y la autoridad competente para deducirla es de naturaleza judicial ordinaria, y nunca-como desafortunadamente ocurre en la práctica-, por vía de un proceso de responsabilidad fiscal, pues el banco no es gestor fiscal, según se ha observado ${ }^{27}$.

Hasta aquí se ha hecho un esfuerzo por registrar los criterios de análisis de los que deben servirse los operadores fiscales para determinar en qué casos un contratista del Estado adquiere la condición de gestor fiscal y, por ende, puede verse sometido a un proceso de responsabilidad cuando, en razón de su dolo o culpa, genera un daño patrimonial al Estado.

El contratista debe ser depositario, en virtud del contrato estatal del que es parte, de la función administrativa de gestionar fondos públicos. Solo habrá disposición de fondos públicos mientras estos no hayan entrado al patrimonio del contratista en virtud del fenómeno del pago. Para que el contratista pueda reputarse como gestor fiscal se requiere que la disponibilidad de los fondos públicos sea cualificada, vale decir, que sobre estos haberes tenga disponibilidad jurídica y no simplemente material. Con base en estos criterios, según se expone en el siguiente acápite, el Consejo de Estado estudió un expediente en el que se discutía si los perjuicios que ocasionó el incumplimiento de un contratista del Estado eran resarcibles por medio del proceso de responsabilidad fiscal. 


\subsection{EL DAÑO GENERADO EN VIRTUD DEL INCUMPLIMIENTO CONTRACTUAL: ¿DAÑO CON RELEVANCIA FISCAL?}

La decisión a la que se hace referencia es la sentencia del 12 de noviembre de 2015, proferida por la Sección Primera del Consejo de Estado, bajo el radicado 1667, con ponencia de María Claudia Rojas Lasso. En ella se estudió el recurso de apelación interpuesto por el apoderado de la Contraloría General de Antioquia contra una sentencia proferida por el Tribunal Administrativo del mismo departamento en la que se declaró la nulidad de dos resoluciones mediante la cuales se había fallado con responsabilidad fiscal en contra de BAAN Colombia Ltda., un contratista del Instituto para el Desarrollo de Antioquia (IDEA).

Los hechos que originaron la controversia fueron los siguientes: entre el IDEA y la sociedad BAAN Colombia Ltda. se celebró, el 23 de diciembre de 1997, un contrato para el desarrollo de software para la implantación de un sistema de información que proporcionaran una solución integral para facilitar la toma de decisiones gerenciales. El IDEA declaró la caducidad administrativa por la ocurrencia de supuestos incumplimientos graves del contrato. Igualmente, el IDEA declaró liquidado el contrato y deudora a BAAN Colombia Ltda. por la suma de \$289.251.240.

Posteriormente, la Unidad Especial de Investigaciones de la Dirección de Responsabilidad Fiscal de la Contraloría General de Antioquia abrió investigación por la existencia de presuntas irregularidades en la contratación celebrada por el IDEA con la firma BAAN Colombia Ltda. En primera instancia se resolvió fallar sin responsabilidad fiscal el proceso. Sin embargo, el Contralor General de Antioquia, en virtud del grado de consulta previsto en el artículo 18 de la Ley 610 de 2000, revocó parcialmente la decisión para, en su lugar, proferir fallo con responsabilidad fiscal en contra de BAAN Colombia Ltda. por la suma de \$1.370.786.508.

El Consejo de Estado identificó que el problema jurídico se contraía a establecer si, en ese caso en particular, BAAN Colombia Ltda., al contratar con el IDEA, ejerció o no gestión fiscal, requisito exigido para poderle reprochar su conducta en un juicio de responsabilidad fiscal. En el fallo se concluyó que el contratista no había ejercido gestión fiscal y, por ende, se confirmó la decisión del juez de primera instancia. Por su importancia, a continuación se transcriben las principales consideraciones que formuló el Consejo de Estado:

La postura del ente de control de Antioquia, es la de considerar que la sociedad BAAN Colombia Ltda. actuó como gestor fiscal, en la medida en que, en virtud de la contratación que suscribió con el IDEA, adquirió la potestad de decisión respec- 
to de los recursos que le fueron entregados para la ejecución de los respectivos objetos contractuales.

La anterior afirmación no es compartida por la Sala, motivo por el que desde ya se anuncia la confirmación del fallo impugnado, como quiera que lo que se observa es que la Contraloría General de Antioquia se equivocó al afirmar en términos absolutos, que la responsabilidad fiscal se configura en todo contrato o proyecto por el hecho de que este involucre recursos públicos, por cuanto se insiste, lo que en el caso en estudio se debió verificar previamente fue si la contratista ejerció o no gestión fiscal. Igualmente se observa que la demandada, confundió el incumplimiento de los contratos en que según la documental aportada incurrió la actora, con el hecho de que producto de dicha contratación, la actora hubiera realizado gestión fiscal para haberle imputado en su contra fallo con responsabilidad fiscal, cuando lo cierto es que se trata de dos supuestos de hecho completamente distintos.

Y no es que la Sala esté desconociendo el hecho, de que el control fiscal puede recaer sobre contratos ya terminados o liquidados como lo ha reconocido la Corte Constitucional, sino que lo que se quiere destacar es que este supuesto fáctico opera siempre y cuando la entidad o persona jurídica declarada responsable fiscal, hubiera desplegado actos de gestión fiscal, supuesto fáctico que en el presente caso no aconteció con la conducta asumida por la demandante, por cuanto esta entidad no manejó ni administró recursos de la parte contratante Instituto para el Desarrollo de Antioquia IDEA como se verá enseguida, sino que asumió unas obligaciones contractuales que no cumplió en su integridad.

[...] Se tiene acreditado que el objeto de los contratos suscritos entre el IDEA y la sociedad BAAN Colombia Ltda., en ningún momento lo constituyó la transferencia de recursos o de fondos o de bienes de propiedad de la contratante a la contratista para que esta los administrara, de tal manera que se le pudiera reconocer el ejercicio de la gestión fiscal. Por el contrario, lo que se observa es que los contratos suscritos se agotaban con la simple ejecución material de unas labores específicas y el suministro de equipos a cargo de la contratista, con tal de dar cumplimiento a los objetos contractuales, pero por manera alguna en el caso sub judice, la contratista asumió actividades propias para el logro de los cometidos estatales del Instituto para el Desarrollo de Antioquia IDEA, situación hipotética que sí hubiera comportado gestión fiscal en cabeza de BAAN Colombia Ltda. ${ }^{28}$.

Esta decisión del Consejo de Estado ratifica que la gestión fiscal de los contratistas del Estado es por definición excepcional, ya que la ejecución de recursos públicos mediante la celebración de contratos públicos no se confunde ni pude confundirse con la atribución de la función administrativa de gestionar fondos del Estado. Y ratifica también que para que un contratista del Estado adquiera 
esa condición, este debe manejar recursos públicos, no privados: si el objeto del contrato se contrae al pago de una suma de dinero por la provisión de bienes o servicios por parte del contratista, este no puede verse sometido a un proceso de responsabilidad así haya incumplido el contrato y así ese incumplimiento haya generado perjuicios patrimoniales a la entidad pública.

Apoyados en los elementos de análisis que hasta acá se han identificado, en el siguiente capítulo se examina un informe de la Contraloría General de la República en el que se identificaron hallazgos con relevancia fiscal que se presentaron en la ejecución de contratos de concesión vial. Con este breve estudio de caso pretendemos demostrar que en no pocas ocasionales las autoridades depositarias de la acción fiscal vinculan a contratistas del Estado a procesos de responsabilidad fiscal sin verificar el cumplimiento de los presupuestos necesarios para endilgarles la calidad de gestores fiscales.

\section{LA RESPONSABILIDAD FISCAL \\ DE LOS CONCESIONARIOS VIALES: UN BREVE ESTUDIO DE CASO}

El 7 de junio de 2012, la Contraloría Delegada para el Sector Infraestructura Física y Telecomunicaciones, Comercio Exterior y Desarrollo Regional remitió a la Agencia Nacional de Infraestructura (ANI) un extenso informe que se produjo a raíz de la auditoría practicada a la entidad, que incluyó la comprobación de que las operaciones financieras, administrativas y económicas se realizaran conforme a las normas legales, estatuarias y de procedimiento aplicables.

Se evaluó la gestión del INCO -hoy ANI- en 11 contratos de concesión de modo carretero, para lo cual se realizó un análisis financiero, legal y técnico de los siguientes contratos de concesión: Santa Marta-Paraguachón, CartagenaBarranquilla, Bogotá-Villavicencio, Pereira-La Victoria, Zipaquirá-Palenque, Córdoba-Sucre, Fontibón-Facatativá-Los Alpes, Desarrollo Vial del Norte, Zona Metropolitana de Bucaramanga, Armenia-Pereira-Manizales y Desarrollo Vial del Oriente de Medellín y Valle de Rionegro.

Producto de la auditoría se detectaron varios hallazgos con relevancia fiscal en virtud de los cuales, posteriormente, la Delegada para Juicios Fiscales y Jurisdicción Coactiva de la Contraloría ordenó la apertura de sendos procesos de responsabilidad fiscal a los que fueron vinculados varios de los concesionarios $^{29}$. Para efectos de este escrito hemos considerado solo uno de dichos hallazgos, con el fin de sondear la procedencia de la acción fiscal en contra de los contratistas del Estado.

29 Este es el caso, por ejemplo, de Autopistas del Café S.A. Este concesionario fue vinculado, mediante auto n. $^{\circ} 00395$ del 13 de abril de 2015, a un proceso de responsabilidad fiscal en el que se identificaron hallazgos por más de $\$ 50.000$ millones de 1996 . 
Uno de los hallazgos con incidencia fiscal corresponde al desplazamiento de las inversiones que se presentó en la ejecución de las obras comprendidas en el alcance del contrato de concesión n. ${ }^{\circ} 002$ de 2007, proyecto vial Córdoba Sucre. Dice al respecto el informe de la Contraloría:

Hallazgo 94. Administrativo, Disciplinario y Fiscal - Alcance Básico Hitos 3, 4 y 6 - Desplazamiento del Cronograma.

El INCO acordó con el concesionario la reprogramación del cronograma de los hitos 3, 4 y 6 del alcance básico del contrato, mediante acta suscrita el 15 de octubre de 2009. Esta variación de cronograma, implica que el concesionario no ejecute las obras de construcción, el mejoramiento, la rehabilitación y los mantenimientos en las fechas y condiciones inicialmente previstas.

Dado que el Estado, a través del componente financiero del proyecto, remunera al concesionario por el cumplimiento de sus obligaciones desde la fecha inicialmente prevista, la modificación del cronograma genera un presunto desequilibrio financiero en contra del Estado y posible favorecimiento al concesionario en un monto estimado de $\$ 821$ millones de 2005, suma que indexada a pesos de diciembre de 2011, asciende a $\$ 1065$ millones [...].

Como resultado de la variación de cronogramas, manteniendo estables las variables como el monto del ingreso esperado y el aporte estatal, se encontró que por efecto del desplazamiento del cronograma de los hitos 3, 4 y 6, las obras se ejecutan en periodos que deben implicar menor remuneración por parte del Estado y varían las condiciones de ejecución de mantenimientos rutinarios y periódicos, circunstancias que implican un incremento del Valor Presente Neto del Alcance Básico del Proyecto en un monto estimado de \$821 millones de 2005, \$1065 millones de $2011^{[30]}$.

El desplazamiento de las inversiones, o del cronograma, como lo denomina la Contraloría, es un fenómeno en virtud del cual las inversiones en obras de construcción, rehabilitación o mantenimiento se ejecutan por parte de los concesionarios de obra pública en periodos distintos a los previstos en el cronograma de inversiones. Este desplazamiento temporal genera, en criterio de la Contraloría, un daño patrimonial al Estado, pues el contratista privado obtiene un beneficio financiero injustificado al postergar la ejecución las inversiones, aun cuando las mismas se le remuneran con el recaudo de peajes como si se hubieran ejecutado conforme el cronograma inicial. Este problema, característico de los contratos de concesión de primera a tercera generación, se presentaba

30 Contraloría General de la República. Delegada para el Sector Infraestructura Física y Telecomunicaciones, Comercio Exterior y Desarrollo Regional. Informe de resultados de auditoría practicada al INCO, CGR-CDIFTCEDR n. ${ }^{\circ} 009$ de junio de 2012, p. 141. 
en la medida que, a diferencia de lo consagrado en la Ley 1508 de 2012, sobre asociaciones públicos-privadas, el derecho a la retribución del contratista no estaba necesariamente ligado a la disponibilidad de la infraestructura.

En el laudo del 13 de enero de 2016, mediante el cual se resolvieron las diferencias entre la ANI y la Concesión Bogotá-Girardot, se hizo referencia a este fenómeno en los siguientes términos:

El desplazamiento en el tiempo de los egresos de un proyecto de concesión vial y la conservación de sus ingresos inalterados en el tiempo incrementa tanto el vPN como la TIR del inversionista por el concepto del valor del dinero en el tiempo, al mantenerse el valor presente de los ingresos mientras se observa una disminución del valor presente de los egresos con respecto a la situación inicial ${ }^{31}$.

Asumamos, en gracia de discusión, que en virtud del desplazamiento de las inversiones el contratista sí obtiene un beneficio económico y que el mismo puede generar una ruptura del equilibrio financiero del negocio concesional en contra de la entidad estatal. Aun asumiendo eso, lo cierto es que ese hecho no tiene la virtualidad de hacer fiscalmente responsable al contratista por el favorecimiento económico que experimenta.

Y no compromete su responsabilidad fiscal por dos razones que ya se han examinado. Porque esa actuación no envuelve actos propios de la gestión fiscal y porque el daño antijurídico que experimentaría la entidad estatal por la ruptura del equilibrio financiero del contrato no es un daño con relevancia fiscal $\mathrm{o}$, por decirlo de otro modo, no es un daño que deba resarcir el contratista mediante un proceso de responsabilidad fiscal, sino a través de un proceso judicial de controversias contractuales.

No hay gestión fiscal, pues los recaudos de peaje con los que los usuarios de la vía concesionada repagan las inversiones del contratista se ceden a título de pago y, por ende, entran a su patrimonio, perdiendo la calidad de fondos públicos. Sobre este punto son particularmente ilustrativas las consideraciones que se plantearon en el laudo que puso fin a las controversias entre CSS Constructores S.A. y la ANI:

Las sumas recibidas por el Contratista en desarrollo del Contrato de Concesión constituyen su remuneración por las prestaciones pactadas y no un encargo de administración de recursos durante la vigencia de la Concesión [...].

Para el Consejo de Estado los dineros entregados al Concesionario son pago a su favor, y extinguen las obligaciones de la entidad cedente. Así se ratifica en el mismo

31 Cámara de Comercio de Bogotá. Laudo arbitral del 13 de enero de 2016, Concesión Autopista Bogotá-Girardot S.A. - CABG contra la Agencia Nacional de Infraestructura, p. 664 . 
pronunciamiento citado, al referirse a la naturaleza y titularidad de los ingresos de la Concesión, especialmente cuando la remuneración del Concesionario se ha pactado a través de la cesión de los derechos de recaudo de peajes.

De lo anterior se concluye que la titularidad de los recursos del Concesionario deviene del hecho de que se entregan a este a título de pago de sus prestaciones y de la obligación de ejecutar la concesión con recursos que le pertenecen, incluidos aquellos que recibe por concepto de recaudo de peajes ${ }^{32}$.

Pero hay más: aun asumiendo que el desplazamiento de las inversiones genera un beneficio financiero para el concesionario que, a su vez, redunda en la alteración del equilibrio económico del contrato, lo cierto es que no es daño que pueda repararse a través de un proceso de responsabilidad fiscal. No puede haber un daño patrimonial al Estado, en el sentido del artículo 6 de la Ley 610 de 2000, al concretarse un beneficio financiero en razón del desplazamiento de las inversiones. Ese no es un hecho que genere una disminución o pérdida de bienes o recursos públicos. Puede ser, sí, un hecho que altere el equilibrio financiero del contrato en razón de que el concesionario se arroga una "utilidad adicional". Pero su restablecimiento es un asunto de competencia exclusiva y excluyente del juez del contrato, no de los entes de control fiscal.

La mejor prueba de que el efecto financiero derivado del desplazamiento de las inversiones no puede ser un daño resarcible a través del proceso de responsabilidad fiscal es la duplicidad de procesos, y la consecuente doble sanción, que se generaría con fundamento en un mismo hecho. La entidad concedente podría reclamar, a través del medio de control de controversias contractuales, que el concesionario reintegre el monto del beneficio financiero que obtuvo para restablecer el equilibrio económico del contrato, y la Contraloría, por su lado, podría condenarlo en un fallo de responsabilidad fiscal al pago de la misma suma.

\section{A MANERA DE CONCLUSIÓN: \\ PAUTAS PARA DETERMINAR SI UN CONTRATISTA DEL ESTADO DESPLIEGA GESTIÓN FISCAL}

La proximidad que hay entre la responsabilidad fiscal y el contrato estatal es evidente. Los contratos que celebran las entidades del Estado son el más importante instrumento de gestión pública y fiscal. Como el contrato estatal involucra la ejecución de recursos públicos, su celebración, ejecución y liquidación es, también, una fuente potencial de daños patrimoniales al Estado. 
Esta contigüidad entre la responsabilidad fiscal y el contrato estatal explica la dificultad que se presenta a la hora de determinar si un contratista del Estado debe responder o no por los daños patrimoniales que sufre el Estado. La cuestión no es sencilla: no existen fórmulas generales y comprensivas, sino que, como ha subrayado el Consejo de Estado, el asunto tiene más notas casuísticas que otra cosa.

A pesar del casuismo que rodea el estudio de la responsabilidad fiscal de los contratistas del Estado, en este escrito se hizo un esfuerzo por determinar las pautas que deben seguir los operadores fiscales en este propósito, y que enumeramos a modo de conclusión:

a. La gestión fiscal de los contratistas del Estado es excepcional, pues de ordinario el contrato estatal es fuente de obligaciones para proveer bienes o servicios a cambio de una contraprestación dineraria, mas no es un título mediante el cual se persiga transferir funciones administrativas -como la fiscal-a sujetos de derecho privado.

b. La gestión fiscal es una función administrativa que se expresa como el poder de gestionar o administrar fondos públicos. Como función administrativa que es, su delegación mediante la celebración de contratos es excepcional.

c. Solamente en los casos en los que el contrato estatal tiene por objeto habilitar a un particular para que sea él y no la entidad estatal el gestor de los recursos públicos, aquel puede verse sometido a un proceso de responsabilidad fiscal.

d. Para que el contratista del Estado se repute gestor fiscal es necesario que el mismo ostente una disponibilidad jurídica y no simplemente material de los recursos públicos. No cualquier disminución, pérdida, uso indebido o malversación de fondos públicos imputable a un contratista del Estado es susceptible de ser reparada mediante el proceso de responsabilidad fiscal. Únicamente cuando el objeto del contrato es la transferencia de la función administrativa de gestionar fondos públicos puede perseguirse, mediante juicio fiscal, la responsabilidad de un contratista del Estado. En los restantes casos, la vía para que se le reparen al Estado los perjuicios que experimenta por la celebración, ejecución o terminación de sus contratos es el proceso judicial.

e. Si bien todo contrato estatal involucra recursos que, en su origen, se califican como públicos, esta condición se conserva o se pierde dependiendo de la finalidad a la que estos se apliquen. Pierde la condición de fondo público el recurso que se destina al pago del contratista, pues el mismo entra a formar parte de su activo patrimonial. Y lo conserva cuando el recurso es administrado por el contratista por cuenta de la entidad estatal.

f. El daño que sufren las entidades del Estado por la inejecución, ejecución defectuosa o el retraso en la ejecución de las obligaciones de su contratista no es un asunto con relevancia fiscal, pues el perjuicio tiene como fuente un ilícito contractual, mas no una conducta que conlleve el ejercicio de la gestión fiscal. 
Por esa misma razón, el desplazamiento de las inversiones en los contratos de concesión de primera generación no puede generar la responsabilidad fiscal de los concesionarios; si acaso, les impone una obligación resarcitoria por la ruptura del equilibrio financiero del contrato.

\section{BIBLIOGRAFÍA}

Agencia Nacional Colombia Compra Eficiente. Exposición de Motivos del Proyecto de Ley por medio del cual se establecen los principios y reglas aplicables a los Procesos de Abastecimiento de bienes, obras y servicios de las Entidades Estatales.

Amaya Olaya, Uriel Alberto. Teoría de la responsabilidad fiscal: aspectos sustanciales y procesales, Bogotá: Universidad Externado de Colombia, 2002

Benavides, José Luis y Santofimio, Jaime Orlando (comps.). Contratación estatal. Estudios sobre la reforma del Estatuto Contractual, Ley 1150 de 2007, Bogotá: Universidad Externado de Colombia, 2009.

Cámara de Comercio de Bogotá. Laudo arbitral del 21 de noviembre de 2016, CSS Constructores S.A. contra Agencia Nacional de Infraestructura.

Cámara de Comercio de Bogotá. Laudo arbitral del 13 de enero de 2016, Concesión Autopista Bogotá-Girardot S.A. - CABG contra la Agencia Nacional de Infraestructura.

Contraloría General de la República, Delegada para el Sector Infraestructura Física y Telecomunicaciones, Comercio Exterior y Desarrollo Regional. Informe de resultados de auditoría practicada al INCO, CGR-CDIFTCEDR n. ${ }^{\circ} 009$ de junio de 2012.

DÁvila, LUIS GUILLERMO. Régimen jurídico de la contratación estatal: aproximación crítica a la Ley 80 de 1993, Bogotá: Legis, 2. ${ }^{a}$ ed., 2003.

De Vivero Arciniegas, Felipe. "La jurisprudencia del Consejo de Estado: añoranza del Decreto 222 de 1983", Revista de Derecho Público de la Universidad de los Andes, n. ${ }^{\circ}$ 12,2001 .

Garrido Falla, Fernando. Tratado de derecho administrativo, Madrid: Tecnos, 7. ${ }^{\text {e ed., }} 1989$.

Giuliani Fonrouge, Carlos. Derecho financiero, Buenos Aires: Ariel, 1996.

NaRAnjo Galves, Rodrigo. Eficacia del control fiscal en Colombia: derecho comparado, bistoria, macroorganizaciones e instituciones, Bogotá: Universidad del Rosario, 2007.

Palacio Jaramillo, María Teresa. "Parámetros constitucionales para la determinación de un régimen jurídico de contratación pública en Colombia", Revista de Derecho Público de la Universidad de los Andes, n. ${ }^{\circ}$ 14, 2002. 
Palacios Mejía, Hugo. El derecho de los servicios públicos. Bogotá: Derecho Vigente, 1999.

Santofimio Gamboa, Jaime. Tratado de derecho administrativo, Bogotá: Universidad Externado de Colombia y Universidad Carlos III de Madrid, 1996.

JURISPRUDENCIA

\section{Corte Constitucional}

Sentencia C-529 de 1993, M.P.: Eduardo Cifuentes Muñoz.

Sentencia C-308 de 1994, M.P.: Antonio Barrera Carbonell.

Sentencia C-167 de 1995, M.P.: Fabio Morón Díaz.

Sentencia C-563 de 1998, M.P.: Carlos Gaviria Díaz.

Sentencia C-619 de 2002, M.P.: Marco Gerardo Monroy Cabra.

\section{Consejo de Estado}

Sala de lo Contencioso Administrativo, Sección Primera. Sentencia del 26 de agosto de 2004, C.P.: Gabriel Eduardo Mendoza. Rad. 2093.

Sala de Consulta y Servicio Civil. Concepto del 3 de febrero de 2005, C.P.: Gustavo Aponte Santos. Rad. 1624.

Sala de lo Contencioso Administrativo, Sección Tercera. Sentencia del 12 de febrero de 2014, C.P.: Mauricio Fajardo Gómez. Rad. 31682.

Sala de lo Contencioso Administrativo, Sección Tercera. Sentencia del 7 de septiembre de 2015, C.P.: Olga Mélida Valle. Rad. 36878.

Sala de lo Contencioso Administrativo, Sección Primera. Sentencia del 12 de noviembre de 2015, C.P.: María Claudia Rojas. Rad. 2004-01667-01. 